Research Article

\title{
Duchesnea indica Extract Attenuates Coal Fly Ash-Induced Inflammation in Murine Alveolar Macrophages through the NF-Kappa B Pathway
}

\author{
H. M. Arif Ullah $\left(\mathbb{D}\right.$, Yuan Yee Lee $\mathbb{D}^{D}$, Sung Dae Kim ${ }^{(D)}$, and Man Hee Rhee \\ Department of Veterinary Medicine, College of Veterinary Medicine, Kyungpook National University, \\ Daegu 41566, Republic of Korea
}

Correspondence should be addressed to Man Hee Rhee; rheemh@knu.ac.kr

Received 23 January 2021; Accepted 21 May 2021; Published 7 June 2021

Academic Editor: Saeideh Saadat

Copyright (c) 2021 H. M. Arif Ullah et al. This is an open access article distributed under the Creative Commons Attribution License, which permits unrestricted use, distribution, and reproduction in any medium, provided the original work is properly cited.

\begin{abstract}
Duchesnea indica is known as false strawberry, is found in East Asia, and has numerous biological properties. The aim of this study was to investigate the anti-inflammatory effect of Duchesnea indica extract (DIE) on coal fly ash- (CFA-) induced inflammation in murine alveolar macrophages (MH-S). Following the induction of inflammation in MH-S cells by CFA, nitric oxide (NO) was measured to evaluate the anti-inflammatory property of DIE. Cell viability and inflammatory gene expression were analyzed using polymerase chain reaction (PCR). The inflammatory pathway in MH-S cells was determined via western blotting and immunofluorescence (IF) analysis. Finally, the major components of the DIE were identified and separated through ultra-performance liquid chromatography (UPLC) and gas chromatography-mass spectrometry (GC-MS) analysis. Our results showed that the DIE dose-dependently inhibited the CFA-induced NO production in MH-S cells. Moreover, the DIE could suppress the CFA-induced proinflammatory mediators, such as cyclooxygenase-2 (COX-2) and inducible nitric oxide synthase (iNOS). In addition, the inhibitory effect of the DIE on proinflammatory cytokines, including interleukin-6 (IL-6), IL- $1 \beta$, and tumor necrosis factor- $\alpha$ $(\mathrm{TNF}-\alpha)$, was detected with PCR. Moreover, the effect of the DIE on the nuclear factor- $\kappa \mathrm{B}(\mathrm{NF}-\kappa \mathrm{B})$ pathway in CFA-activated $\mathrm{MH}-\mathrm{S}$ cells was measured via western blotting. Furthermore, the inhibition of the phosphorylated NF- $\kappa \mathrm{B}(\mathrm{p}-\mathrm{NF}-\kappa \mathrm{B})$ translocation was analyzed using IF assay. The findings of this study indicated that the DIE potentially inhibited the CFA-induced inflammation by blocking the NF- $\kappa \mathrm{B}$ inflammatory signaling pathway in MH-S cells and that the DIE might contain favorable anti-inflammatory compounds which may be effective in attenuating lung inflammation.
\end{abstract}

\section{Introduction}

Coal fly ash (CFA) is a major environmental factor of air pollution, which is produced regularly due to industrial activities and the use of motor vehicles in the urban areas [1]. CFA consists of liquid and solid particulate matters that vary in size and origin, including coal, combustion particles, and asbestos $[1,2]$. Nanoparticles can retain for a long period of time in the atmosphere and easily move in the air. Chronic exposures of CFA can cause accumulation of sediments in the lungs and lead to serious adverse effects, such as inflammation in the alveolar cells [3, 4]. Moreover, nanoparticles are responsible for many respiratory diseases, such as asthma, bronchitis, chronic obstructive pulmonary diseases (COPD), and lung carcinoma [5].

Inflammation is an important biological response to harmful stimuli and the first line of defense in the immune system [6]. Alveolar macrophages (AM) are considered one of the defensive cell populations in the lungs and facilitate regulating lung inflammation and host defense protection against airborne nanoparticles [7]. After CFA invades the airway of the lungs, AM are recruited, resulting in the production of inflammatory mediators and cytokines, which is the initial response of the immune system [8]. CFA-induced excessive proinflammatory cytokines are considered one of the major causes of lung diseases. They can be 
regulated by the activation of the transcription factors, such as nuclear factor kappa-B (NF- $\kappa \mathrm{B})$ signaling cascade $[9,10]$.

Duchesnea indica is a perennial plant that belongs to the Rosaceae family and is widely distributed in Asian countries especially in Bangladesh, China, Japan, and Korea [11]. It has been extensively used as a folk medicine in Asia for its unique biological properties including antioxidative, antiinflammatory, antimutagenic, and anticancerous properties $[12,13]$. Several studies have demonstrated that some phenolic compounds, such as phenolic acid, flavonoids, and ellagic acid, are the main pharmacologically bioactive constituents in Duchesnea indica [11]. It has been shown that the Duchesnea indica extract (DIE) downregulates cervical cancer through apoptosis and cell cycle arrest [14]. Moreover, previous studies have reported that the DIE protected the skin fibroblast of humans against hydrogen peroxideinduced cytotoxicity and inhibited the growth of human cancer cells in vitro [15]. Thus, traditional medicines have been considered by the patients due to their therapeutic effects and bioactive ingredients [16].

In this study, we aimed to investigate the anti-inflammatory effects of the DIE on CFA-induced inflammation in MH-S cells. Taken together, our results demonstrated that the DIE can prevent the inflammation in CFA-activated MH-S cells, and such activity is mediated by inhibiting the expression of proinflammatory mediators and cytokines.

\section{Materials and Methods}

2.1. Chemicals and Reagents. The following chemicals and reagents were utilized: Roswell Park Memorial Institute Medium (RPMI), fetal bovine serum (FBS), penicillinstreptomycin, and Dulbecco's phosphate buffered saline (DPBS) (Welgene, South Korea); CFA and 3-(4,5-dimethylthiazol-2-yl)-2,5-diphenyltetrazolium bromide (MTT) (Sigma-Aldrich, St. Louis, MO, USA); Oligo-dT (Bioneer oligo synthesis); COX-2, iNOS, TNF- $\alpha$, IL- $1 \beta$, and IL-6 primers (Bioneer, Daejeon, South Korea); dimethyl sulfoxide (DMSO) (Sigma-Aldrich, St. Louis, MO, USA); TRIzol reagent (Invitrogen, Carlsbad, CA, USA); Pro-prep (iNtRON biotechnology, South Korea); bovine serum albumin (BSA) (Thermo Fisher Scientific, South Korea); specific antibodies used for western blot, including COX-2, iNOS, $\mathrm{p}$-IKB, p-NF- $\kappa \mathrm{B}, \beta$-actin, and HRP-conjugated secondary antibody (Cell Signaling Technology, Danvers, MA, USA); secondary antibody used for immunofluorescence (antirabbit IgG Fab2, Alexa Fluor 555, Molecular Probes). All other chemicals and reagents were the highest quality available.

2.2. Preparation of the Duchesnea indica Ethanol Extract (DIE). We purchased dried Duchesnea indica leaves and stems from the company, ground them into fine coarse powder, and extracted them in $70 \%$ ethanol (1-part dry weight of plant to 20-parts of solvent ratio) using a heating mantle (Model: MS-DM604, MTOPS, South Korea) at $80^{\circ} \mathrm{C}$ for $2 \mathrm{~h}$. Then, the extract was filtered using the Whatman filter paper, followed by extract condensation using the rotary evaporator system (Heating bath-B100 and Rotavapor-R100, BUCHI, Switzerland). Finally, the crude extract was frozen overnight at $-70^{\circ} \mathrm{C}$ and lyophilized using a freeze dryer (Model: FDU-7012, Operon, South Korea) to obtain dry fine powder. The yields were weighed and preserved at $-30^{\circ} \mathrm{C}$ for use in experiments. At the time of the experiment, the powder was dissolved in DMSO with different doses of DIE $(12.5,25,50$, and $100 \mu \mathrm{g} / \mathrm{mL})$.

2.3. UPLC-QTOF-MS Analysis of DIE. UPLC analysis of the DIE was performed using ACQUITY UPLC ${ }^{\mathrm{TM}}$ (Waters Corp., Milford, MA, USA), equipped with a binary solvent delivery system and coupled to the quadrupole time-of-flight mass spectrometer (Q-TOF Premier ${ }^{\mathrm{TM}}$, Waters Corp., Milford, MA, USA) equipped with an auto-sampler and a UV detector. Briefly, the DIE $(2 \mu \mathrm{L})$ was injected into the ACQUITY UPLC BEH C18 chromatography column $(2.1 \times 100 \mathrm{~mm} \times 1.7 \mu \mathrm{m})$. The column temperature was fixed at $35^{\circ} \mathrm{C}$, and the flow rate was $0.4 \mathrm{~mL} / \mathrm{min}$. The chromatographic gradient consisted of mobile phases: (A) water with $1 \%$ formic acid and (B) acetonitrile with $1 \%$ formic acid. The gradient duration was optimized: $0 \mathrm{~min}, 10 \% \mathrm{~B} ; 0-11 \mathrm{~min}$, $10 \%-90 \% \mathrm{~B} ; 11-11.5 \mathrm{~min}, 90 \%-100 \% \mathrm{~B} ; 11.5-13.5 \mathrm{~min}$, $100 \% \mathrm{~B}$; and $13.5-15 \mathrm{~min}$, back to $10 \% \mathrm{~B}$. The mass spectrometer condition was a negative ion mode with the capillary and cone voltages being $2.3 \mathrm{kV}$ and $50 \mathrm{~V}$, respectively. $\mathrm{N}_{2}$ was used as a desolvation gas. The source temperature was $100^{\circ} \mathrm{C}$, and the desolvation temperature was $350^{\circ} \mathrm{C}$. Leucine-enkephalin was used as a reference compound $(\mathrm{m} / \mathrm{z} 554.2615)$ in the form of a spray.

2.4. GC-MS Analysis of DIE. GC-MS analysis of the DIE was performed using the Agilent 7890A GC (Agilent Technologies, Santa Clara, CA, USA). The GC-MS device was equipped with a $30 \mathrm{~m} \times 0.25 \mathrm{~mm}$ (i.d. DB-5MS) chromatography column and the Agilent 5975C mass selective detector to separate and quantify the compounds of DIE. The extract was injected at $250^{\circ} \mathrm{C}$. The temperatures for the transfer line and source were $280^{\circ} \mathrm{C}$ and $230^{\circ} \mathrm{C}$, respectively. The column temperature was set at $70^{\circ} \mathrm{C}$ as an initial temperature for $1 \mathrm{~min}$ and raised to $300^{\circ} \mathrm{C}$ at a rate of $5^{\circ} \mathrm{C} /$ min, with duration at a final temperature of $300^{\circ} \mathrm{C}$ for $30 \mathrm{~min}$. The mass spectrometry was acquired via electron ionization and scan modes. The helium gas was used as a carrier gas with a constant flow rate $(1 \mathrm{~mL} / \mathrm{min})$.

2.5. Cell Culture. The MH-S cell line, originating from the American Type Culture Collection, was cultured in RPMI supplemented with $10 \% \mathrm{FBS}, 100 \mathrm{IU} / \mathrm{mL}$ penicillin, and $100 \mu \mathrm{g} / \mathrm{mL}$ streptomycin sulfate (Welgene, South Korea). The incubation conditions were maintained at $37^{\circ} \mathrm{C}$ and $5 \%$ $\mathrm{CO}_{2}$ during culture and treatment conditions.

2.6. Nitric Oxide (NO) Assay. NO was measured using the Griess reagent $\mathrm{A}(0.2 \% \mathrm{~N}$-ethylenediamine dihydrochloride) and Griess reagent B (2\% sulfanilamide in $5 \%$ phosphoric acid) reaction methods. Briefly, the MH-S macrophages 
were seeded in a 24-well plate and incubated with or without CFA $(2.5 \mu \mathrm{g} / \mathrm{mL})$ in the absence or presence of the DIE (12.5, 25,50 , and $100 \mu \mathrm{g} / \mathrm{mL}$ ) at indicated concentrations for $18 \mathrm{~h}$. The Griess reagents $(100 \mu \mathrm{L})$ were added with cell culture supernatants $(100 \mu \mathrm{L})$ and incubated for $5 \mathrm{~min}$ at normal condition. Then, absorbance was measured in a microplate reader at $540 \mathrm{~nm}$ (Versamax, Microplate Reader, Molecular devices, CA, USA).

2.7. Cell Viability Assay. To determine the cytotoxicity of the extract, a cell viability assay was measured as described using $100 \mu \mathrm{L} /$ well of 3-(4,5-dimethylthiazol-2-yl)-2, and 5-diphenyltetrazolium bromide (MTT) reagent was added to the culture medium [17]. After $2-3 \mathrm{~h}$ of incubation at $37^{\circ} \mathrm{C}$ in $5 \%$ $\mathrm{CO}_{2}$, the supernatants were discarded, and dimethyl sulfoxide (DMSO) $(100 \mu \mathrm{L} /$ well) was added and then incubated at room temperature with shaking for $10 \mathrm{~min}$. Finally, absorbance was analyzed using microplate reader at $560 \mathrm{~nm}$ (Versamax, Microplate Reader, Molecular devices, CA, USA).

2.8. RNA Extraction, Reverse Transcription-Polymerase Chain Reaction (RT-PCR), and Real-Time qRT-PCR. PCR analysis was conducted in accordance with the previously reported method [18]. The murine macrophages (MH-S) were treated with or without the DIE $(12.5,25,50$, and $100 \mu \mathrm{g} / \mathrm{mL}$ ) for $30 \mathrm{~min}$ at indicated concentrations, followed by the CFA stimulation $(2.5 \mu \mathrm{g} / \mathrm{mL})$ for $18 \mathrm{~h}$. RNA was collected from cells using TRIzol reagent (Invitrogen, Carlsbad, CA, USA). Two micrograms of total RNA was annealed with Oligo-dT (Bioneer, South Korea) for $10 \mathrm{~min}$ at $70^{\circ} \mathrm{C}$, cooled for $5 \mathrm{~min}$ in ice, and then reverse-transcribed using reverse transcriptase premix (Bioneer, South Korea) in $20 \mu \mathrm{L}$ of reaction mixture for $90 \mathrm{~min}$ at $42.5^{\circ} \mathrm{C}$ on a thermocycler. To inactivate the reverse transcriptase, the reaction was terminated at $95^{\circ} \mathrm{C}$ for $5 \mathrm{~min}$. RT-PCR was performed using cDNA obtained from RT reaction in a PCR premix (Bioneer, South Korea). Moreover, the PCR products were electrophoresed on agarose gel $(1 \%)$ stained with ethidium bromide. The band was visualized using ImageQuant LAS 500 (GE Health Care Life Sciences, South Korea). The intensity of the band density was normalized to GAPDH. Real-time PCR was performed using SYBR green. Table 1 shows the RT-PCR and real-time PCR primer sequences.

2.9. Western Blot Analysis. Western blot analysis was conducted in accordance with the previously reported method [10]. MH-S cells were untreated (control group), treated with only CFA $(2.5 \mu \mathrm{g} / \mathrm{mL})$, and treated with the DIE (12.5, $25,50$, and $100 \mu \mathrm{g} / \mathrm{mL})$ in the presence of CFA $(2.5 \mu \mathrm{g} / \mathrm{mL})$. The proteins were extracted from the cells with the protein extraction solution, Pro-Prep (iNtRON biotechnology, South Korea). Then, the proteins were determined using the protein measurement solution, PRO-MEASURE assay kit (iNtRON biotechnology, South Korea). The cell lysates were then subjected to SDS-PAGE (10\%) and transferred onto the
PVDF membranes (Millipore, Immobilion-P, Billerica MA, USA). Membranes were blocked for $1 \mathrm{~h}$ in $5 \%(w / v)$ skim milk and $0.1 \%(v / v)$ Tween-20 in TBS. Then membranes were incubated with different primary antibodies overnight at $4^{\circ} \mathrm{C}$. After washing, $1 \mathrm{~h}$ of incubation with horse radish peroxidase- (HRP-) labelled secondary antibody $(1: 3000$ dilution, Cell Signaling) at room temperature was performed. Proteins were detected using enhanced chemiluminescence (ECL) solution (Supex, Daegu, Korea). Immunoblots were quantified using the ImageJ software.

2.10. Immunofluorescence Staining. Immunofluorescence (IF) assay was done as described [19]. MH-S cells were washed with DPBS and fixed with $4 \%$ paraformaldehyde (PFA) for 10 minutes. Moreover, the cells were permeabilized with $0.2 \%$ triton X-100 in TBS (TBST) for 10 minutes and washed with TBST for 5 minutes every three times. Using $2 \% \mathrm{BSA}$, the samples were blocked for $1 \mathrm{~h}$, and primary antibody rabbit anti p-NF- $\kappa$ B (Cell Signaling Technology, Danvers, MA, USA) was applied to the cells at $4^{\circ} \mathrm{C}$ overnight. The cells were washed with TBST for 5 minutes every three times. The samples were incubated with secondary antibody (anti-rabbit IgG Fab2, Alexa Fluor 555, Molecular Probes) for 1 hour in the dark, and after washing with TBST three times, the samples were mounted using ProLong Gold Antifade Reagent with DAPI to visualize the nuclei (Cell Signaling Technology, Danvers, MA, USA) and analyzed via confocal microscopy (ZEISS).

2.11. Statistical Analysis. Data were analyzed by one-way ANOVA or unpaired Student's $t$-test followed by Dunnett's multiple comparison tests using the GraphPad Prism software. Data are presented as mean \pm SEM. The statistical significance is denoted as ${ }^{*} p<0.05,{ }^{* *} p<0.01$, and ${ }^{* * *} p<0.001$ or $\mathrm{ns}=$ not significant.

\section{Results}

3.1. Active Compositions of the DIE Based on the UPLC-QTOF-MS and GC-MS Analyses. Active compounds in the DIE were determined via ultra-performance liquid chromatography (UPLC) analysis. Based on the results of the UPLC-QTOF-MS analysis, the main active compound of the DIE was ellagic acid (Figure 1). A previous study reported that phenolic compounds, such as ellagic acid, phenolic acid, and flavonoids, are the major active compounds in Duchesnea indica [20-22]. Moreover, based on the results of the gas chromatography-mass spectrometry (GC-MS) analysis, the major components were as follows: gamma-sitosterol; hexadecanoic acid; linoelaidic check spacing acid; octadecanoic acid; 9, 12, 15-octadecatrienoic acid; and 2, 3-dihydro-3, 5-dihydroxy-6-methyl-(4H)-pyran-4-one (Table 2).

3.2. DIE Protects CFA-Induced Nitric Oxide Production and Cell Death in MH-S Macrophages. Nitric oxide (NO) is an important mediator in the inflammatory condition, and excessive production of NO contributes to inflammatory 
TABle 1: Primer used for RT-PCR and real-time PCR analysis.

\begin{tabular}{lrc}
\hline RT-PCR & Forward primer sequences $\left(5^{\prime}-3^{\prime}\right)$ & Reverse primer sequences $\left(5^{\prime}-3^{\prime}\right)$ \\
\hline COX-2 & CACTACATCCTGACCCACTT & ATGCTCCTGCTTGAGTATGT \\
iNOS & CCCTTCCGAAGTTTCTGGCAGCAGC \\
IL-6 & GTACTCCAGAAGACCAGAGG & GGCTGTCAGAGCCTCGTGGCTTTGG \\
TNF- $\alpha$ & TTGACCTCAGCGCTGAGTTG & TGCTGGTGACAACCACGGCC \\
IL- $1 \beta$ & CTGTGGAGAAGCTGTGGCAG & CCTGTAGCCCACGTCGTAGC \\
GAPDH & CACTCACGGCAAATTCAACGGCAC & GGGATCCACACTCTCCAGCT \\
Real-time PCR & & GACTCCACGACATACTCAGCAC \\
COX-2 & GGCAGCCTGTGAGACCTTTG & \\
iNOS & GGCAGCCTGTGAGACCTTTG & GCATTGGAAGTGAAGCGTTTC \\
TN-6 & TCCAGTTGCCTTCTTGGGAC & GCATTGGAAGTGAAGCGTTTC \\
IL- $1 \beta$ & TGCCTATGTCTCAGCCTCTTC & GTGTAATTAAGCCTCCGACTTG \\
GAPDH & CAACCAACAAGTGATATTCTCCATG & GAGGCCATTTGGGAACTTCT \\
& CACTCACGGCAAATTCAACGGCAC & GATCCACACTCTCCAGCTGCA \\
\hline
\end{tabular}

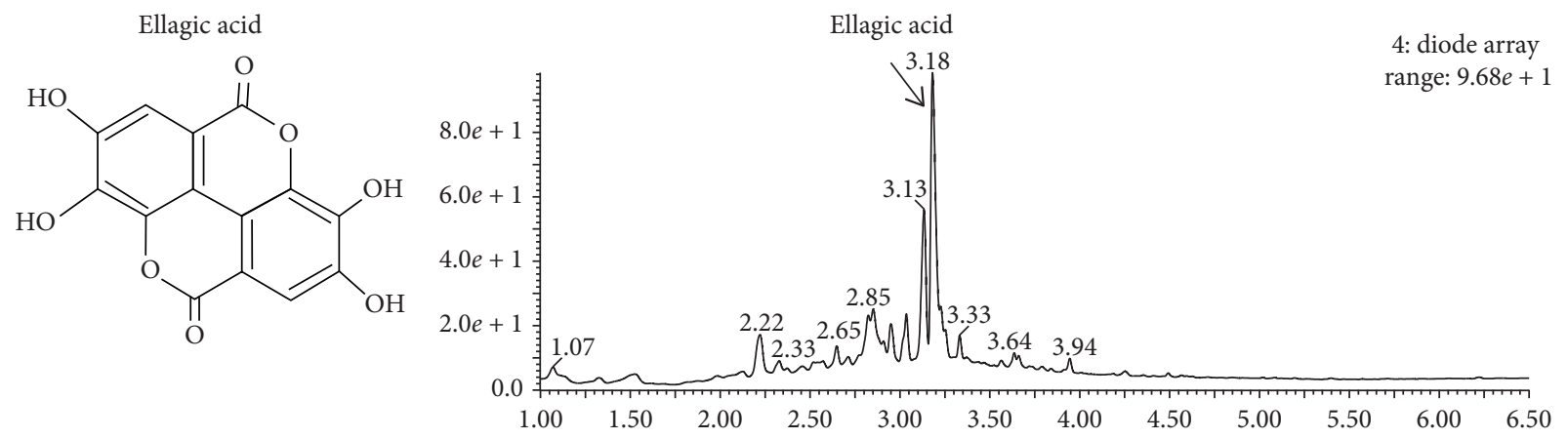

(a)

(b)

FIgure 1: Chemical compositions of the Duchesnea indica extract (DIE). (a) Chemical structure of ellagic acid. (b) Ellagic acid was identified via UPLC-QTOF-MS analysis as a major compound, and the retention time was $3.18 \mathrm{~min}$.

TABLE 2: Major compounds in the Duchesnea indica extract identified via GC-MS analysis.

\begin{tabular}{lc}
\hline Compounds & Area (\%) \\
\hline 2,3-Dihydro-3,5-dihydroxy-6-methyl-(4H)-pyran-4- & 20.37 \\
one & 18.04 \\
Hexadecanoic acid & 11.1 \\
9,12,15-Octadecatrienoic acid & 7.25 \\
Gamma-sitosterol & 5.52 \\
Octadecanoic acid & 4.54 \\
Linoelaidic acid & \\
\hline
\end{tabular}

diseases $[23,24]$. In this study, the levels of NO in response to CFA in $\mathrm{MH}-\mathrm{S}$ murine AM were measured using the Griess reaction method. The DIE potently inhibited the NO induction in a dose-dependent manner (Figure 2(a)). MTT assay was performed to determine the cell viability assay, and the results showed that the DIE did not affect the cell viability at the used concentration (Figure 2(b)). These results demonstrated that the DIE inhibited the NO production dose-dependently, and the used concentrations did not show cytotoxicity.

3.3. Preventive Effect of the DIE on CFA-Induced Proin-
flammatory Cytokines in MH-S Macrophages. Pretreatment of MH-S with the DIE for $30 \mathrm{~min}$ decreased the levels of CFA-induced proinflammatory mediators and cytokines. The mRNA levels of proinflammatory mediators such as inducible nitric oxide synthase (iNOS) and cyclooxygenase-2 (COX-2) and proinflammatory cytokines including interleukin-6 (IL-6), IL- $1 \beta$, and tumor necrosis factor- $\alpha$ (TNF- $\alpha$ ) were analyzed using RT-PCR to investigate the anti-inflammatory properties of the DIE. The results showed that proinflammatory mediators and cytokines were dose-dependently reduced at the mRNA level (Figures 3(a)$3(f))$. This finding suggested that the DIE downregulated the CFA-induced inflammatory cytokines and significantly reduced the mRNA levels mainly at concentrations of 50 and $100 \mu \mathrm{g} / \mathrm{ml}$.

3.4. DIE Ameliorates the CFA-Induced mRNA Expression of Proinflammatory Cytokines in MH-S Macrophages. To confirm the results of the RT-PCR on the proinflammatory mediators and cytokines in MH-S cells, the mRNA expressions of the proinflammatory mediators were investigated and the proinflammatory cytokines were analyzed with real-time PCR. The mRNA expressions of the proinflammatory mediators and cytokines were noticeably dosedependently downregulated with the DIE treatment (Figures 4(a)-4(e)). Taken together, the real-time PCR results suggested that the DIE reduced the inflammation in a concentration-dependent manner. 


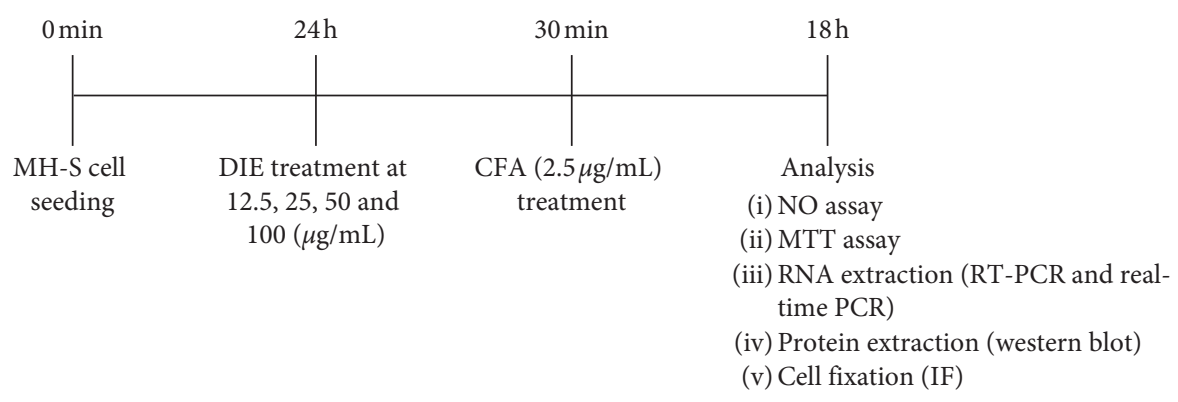

(a)

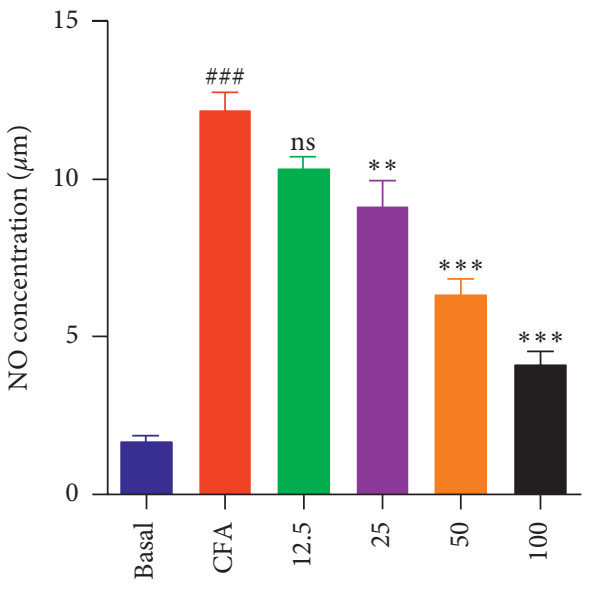

(b)

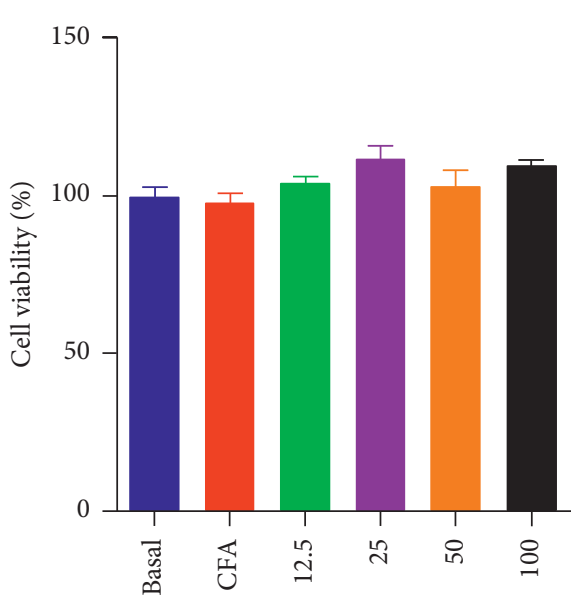

(c)

FIGURE 2: Effect of the Duchesnea indica extract (DIE) on coal fly ash- (CFA-) induced NO production and cell viability in murine alveolar macrophages (MH-S). (a) Schematic diagram of this study. The cells were in six groups including the basal (control) group, only CFA $(2.5 \mu \mathrm{g} / \mathrm{mL})$ group, and CFA with the DIE $(12.5,25,50$, and $100 \mu \mathrm{g} / \mathrm{mL})$ group. Cells were treated with the above concentrations of the DIE for $30 \mathrm{~min}$ prior to the CFA treatment $(2.5 \mu \mathrm{g} / \mathrm{mL}$ ) and incubated for $18 \mathrm{~h}$. (b) NO level was determined using the Griess reagent method. (c) Cell viability assay was performed using the MTT reagent method. The cells were seeded in a 24 -well plate. All values were expressed as standard error of mean $\pm(\mathrm{SEM})$ from three independent experiments. ${ }^{\# \# \#} p<0.001$ when compared with basal group; ${ }^{*} p<0.05$, ${ }^{* *} p<0.01$, and ${ }^{* * *} p<0.001$ when compared with the only CFA-treated group.

3.5. DIE Inhibits the Activation of $N F-\kappa B$ Signaling in CFATreated $M H-S$ Macrophages. The effects of the DIE on nuclear factor $-\kappa \mathrm{B}(\mathrm{NF}-\kappa \mathrm{B})$ signaling were measured as a transcription factor has an important role in inflammation. The activation with CFA leads to the inflammatory pathway, wherein NF- $\kappa \mathrm{B}$ signaling is a key axis in the inflammatory mechanism $[1,9]$. Treatment with CFA significantly induced the phosphorylation of $\mathrm{NF}-\kappa \mathrm{B}$ and inhibitor of kappa-B $(\mathrm{I} \kappa \mathrm{B})$, whereas the pretreatment of the DIE significantly inhibited the phosphorylation of NF- $\kappa \mathrm{B}$ and $\mathrm{I} \kappa \mathrm{B}$ in $\mathrm{MH}-\mathrm{S}$ cells (Figures 5(d) and 5(e)). This result suggested that the pretreatment with the DIE markedly downregulated the phosphorylation of the CFA-induced NF- $\kappa \mathrm{B}$ and $\mathrm{I} \kappa \mathrm{B}$ activation in $\mathrm{MH}-\mathrm{S}$ cells.

3.6. DIE Inhibits the Translocation of NF- $\kappa B$ in CFA-Treated $M H-S$ Macrophages. To find out whether the anti-inflammatory activities of the DIE are mediated by the NF- $\kappa \mathrm{B}$ signal transduction pathway in CFA-activated $\mathrm{MH}-\mathrm{S}$ cells, the translocation of the activated $\mathrm{p}-\mathrm{NF}-\kappa \mathrm{B}$ from the cytoplasm to the nucleus was determined via immunofluorescence (IF) assay. The treatment with CFA increased the translocation of NF- $\kappa \mathrm{B}$ from the cytoplasm to the nucleus, whereas the treatment with highest dose of DIE $(100 \mu \mathrm{g} / \mathrm{mL})$ significantly suppressed the nuclear translocation of $\mathrm{p}-\mathrm{NF}$ $\kappa \mathrm{B}$ in activated $\mathrm{MH}-\mathrm{S}$ cells (Figure 6 ). Bay-11 was used as an $\mathrm{NF}-\kappa \mathrm{B}$ inhibitor. The results of the IF assay indicated that the anti-inflammatory properties of the DIE were associated with its inhibitory effects on the phosphorylation of the NF$\kappa \mathrm{B}$ signal pathway (Figure 7 ).

\section{Discussion}

Duchesnea indica has been widely used as a natural medicine in Asia especially in Bangladesh, China, Korea, and Japan for the prevention and treatment of numerous diseases, such as tissue inflammation, leprosy, congenital fever, and mainly cancer $[12,14]$. Earlier studies have shown that its antiinflammatory agents can suppress transcription factors, such as nuclear factor $-\kappa \mathrm{B}(\mathrm{NF}-\kappa \mathrm{B})$ and function as a key regulator in inflammatory cascade $[2,7,9]$. In the present study, we examined the effects of Duchesnea indica on CFA-induced inflammation in the MH-S cell line.

Pharmacological studies have demonstrated that phenolic ingredients are the main bioactive compounds in the 


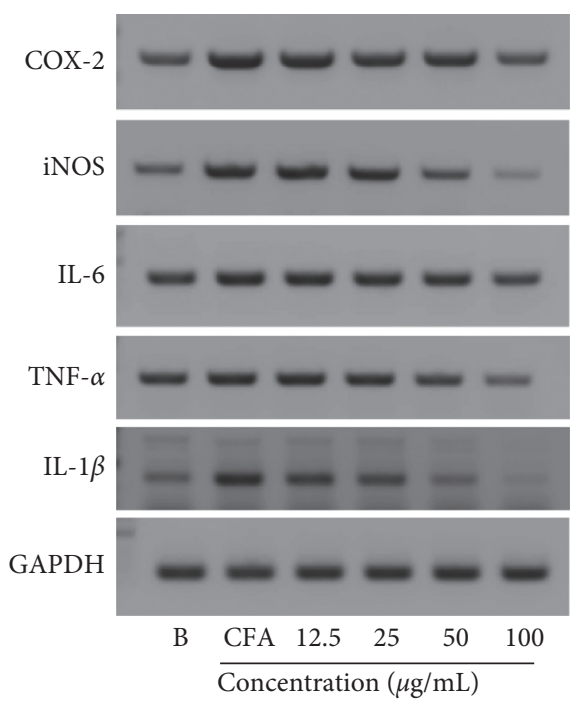

(a)

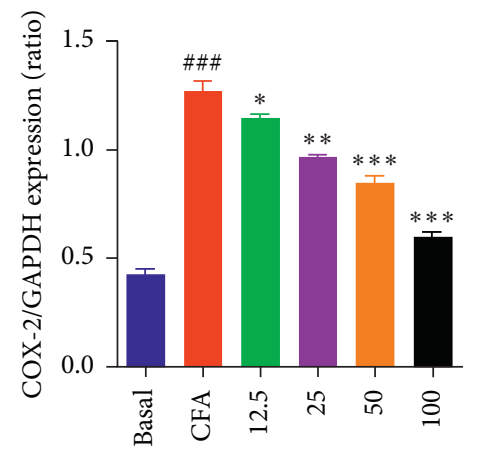

(b)

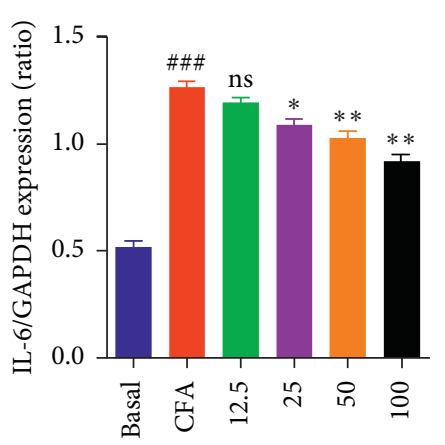

(d)

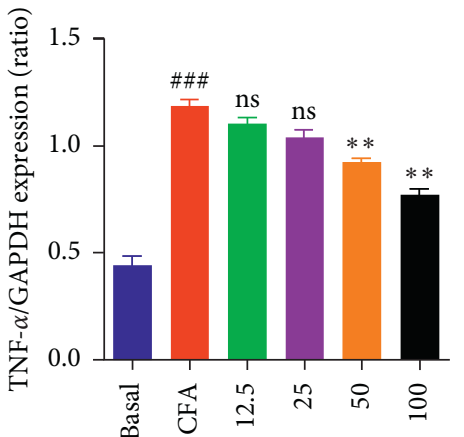

(e)

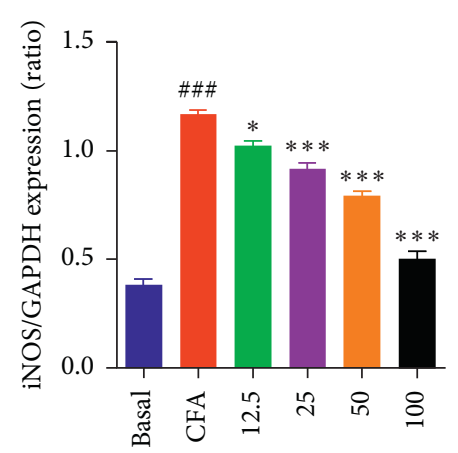

(c)

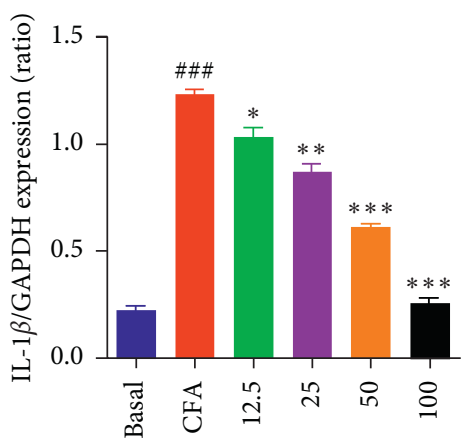

(f)

FIGURE 3: Effect of the DIE on CFA-induced proinflammatory mediators and cytokines in MH-S cells analyzed via RT-PCR. (a) After 18 h of incubation with CFA $(2.5 \mu \mathrm{g} / \mathrm{mL})$, the mRNA levels of the proinflammatory mediators (COX-2 and iNOS) and proinflammatory cytokines (IL-6, TNF- $\alpha$, and IL-1 $\beta$ ) and GAPDH (housekeeping gene) were determined via reverse transcription-polymerase chain reaction (RTPCR). (b-f) Densitometric analysis of relative mRNA expression levels which were quantified using the ImageJ program. The cells were seeded in a 6-well plate, and the doses of DIE were used as $12.5,25,50$, and $100 \mu \mathrm{g} / \mathrm{mL}$. All values were expressed as standard error of mean $\pm(\mathrm{SEM})$ from three independent experiments. ${ }^{\# \#} p<0.001$ when compared with the basal group; ${ }^{*} p<0.05,{ }^{* *} p<0.01$, and ${ }^{* * *} p<0.001$ when compared with the only CFA-treated group.

DIE [11]. Ellagic acid was indicated as the main compound of the DIE via the UPLC-QTOF-MS analysis. It is a phenolic compound and has been reported to exert a variety of biological properties, such as antioxidant, anti-inflammatory, and anticoagulant effects $[25,26]$. Moreover, ellagic acid has also been shown to reverse hepatic damage by inhibiting the
NF- $\kappa \mathrm{B}$ signaling pathway [27]. Previous findings are consistent with our study and suggest that ellagic acid could be one of the major active components responsible for any antiinflammatory activity. The major compounds in the DIE were determined via GC-MS analysis: 2, 3-dihydro-3, 5dihydroxy-6-methyl-(4H)-pyran-4-one; hexadecanoic acid; 


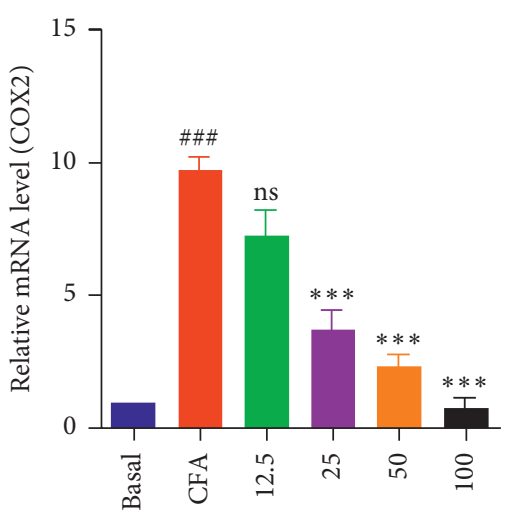

(a)

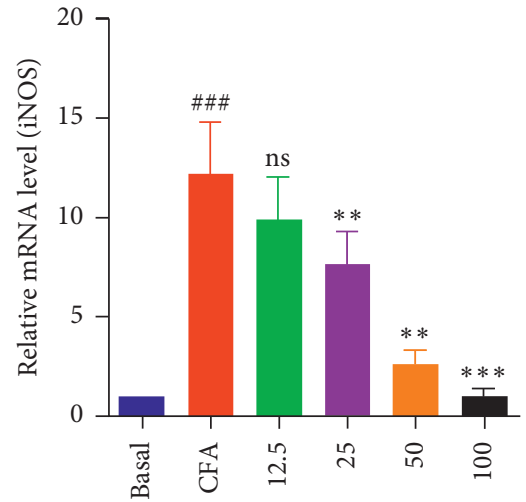

(b)

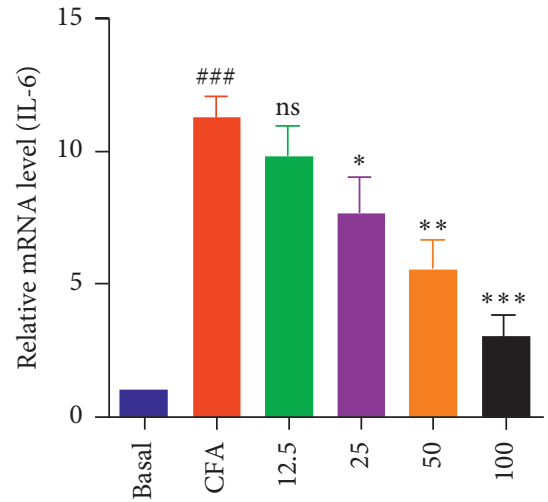

(c)

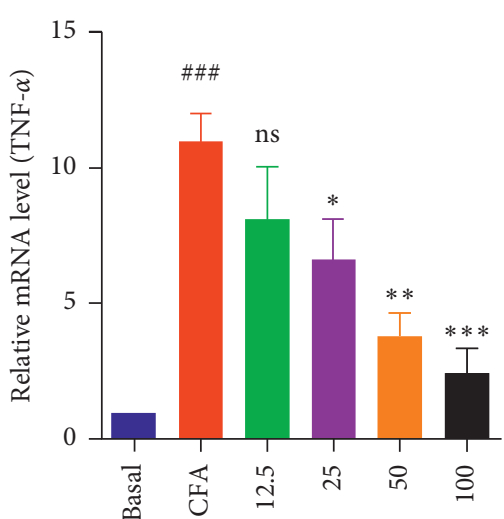

(d)

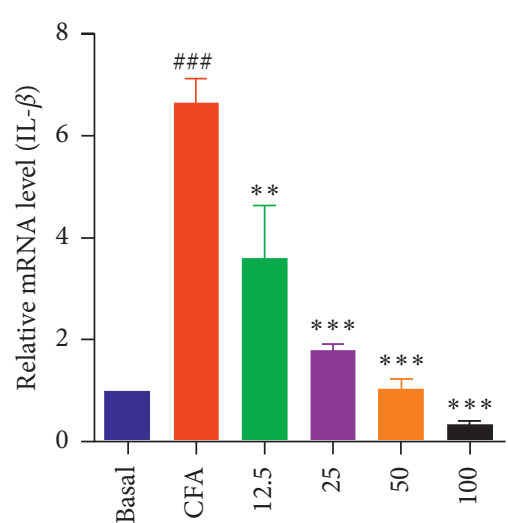

(e)

FIGURE 4: Effect of the DIE on CFA-induced mRNA expression in MH-S cells measured by real-time PCR. (a-e) After $18 \mathrm{~h}$ of incubation with CFA $(2.5 \mu \mathrm{g} / \mathrm{mL})$, the mRNA levels of COX-2, iNOS, IL-6, TNF- $\alpha$, and IL- $1 \beta$ were analyzed via quantitative real-time PCR. GAPDH was used as a control gene. The cells were seeded in a six-well plate, and the doses of DIE were used as $12.5,25,50$, and $100 \mu \mathrm{g} / \mathrm{mL}$. All values were expressed as standard error of mean \pm (SEM) from three independent experiments. ${ }^{\# \# \#} p<0.001$ when compared with basal group; ${ }^{*} p<0.05,{ }^{* *} p<0.01$, and ${ }^{* * *} p<0.001$ when compared with the only CFA-treated group.

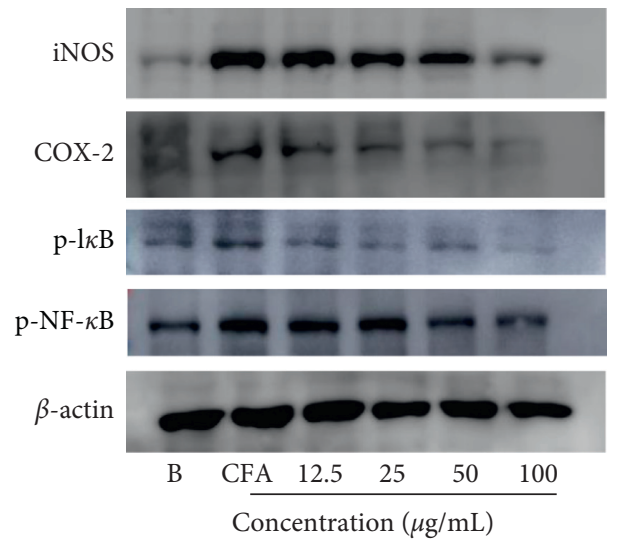

(a)

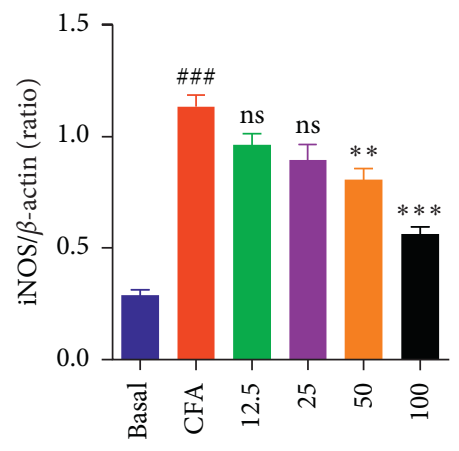

(b)

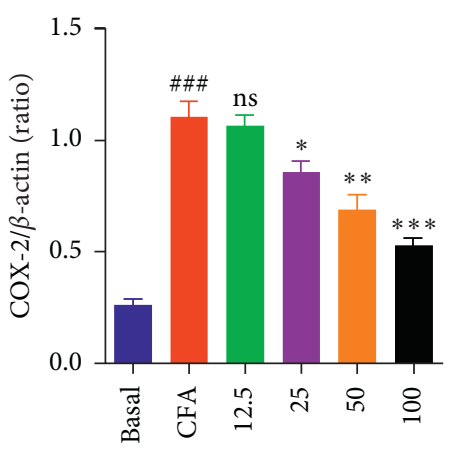

(c)

FIgURE 5: Continued. 


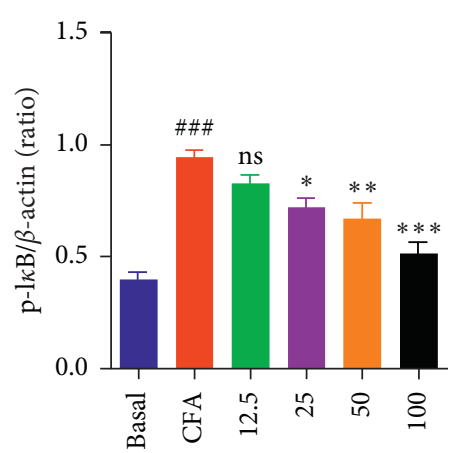

(d)

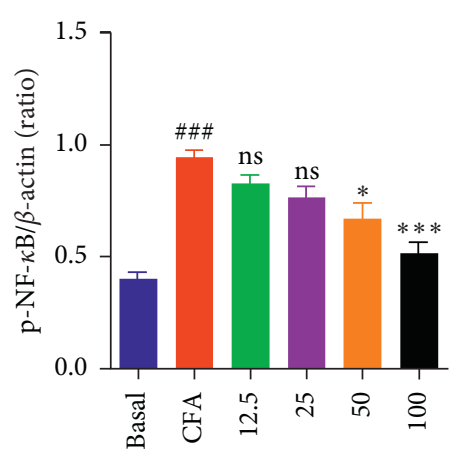

(e)

FIgUre 5: Effect of the DIE on CFA-induced NF- $\kappa$ B phosphorylation in MH-S cells. (a) After $18 \mathrm{~h}$ of incubation with CFA (2.5 $\mu \mathrm{g} / \mathrm{mL}$ ), the protein levels of iNOS, COX-2, $\mathrm{p}-\mathrm{I} \kappa \mathrm{B}$, and $\mathrm{p}-\mathrm{NF} \kappa \mathrm{B}$ were determined using western blot. $\beta$-Actin was used as a loading control. (b-e) Densitometric analysis of protein expression levels which were measured using the ImageJ software. The cells were seeded in a six-well plate, and the doses of DIE were used as $12.5,25,50$, and $100 \mu \mathrm{g} / \mathrm{mL}$. All values were expressed as standard error of mean $\pm($ SEM) from three independent experiments. ${ }^{*} p<0.05,{ }^{* *} p<0.01$, and ${ }^{* * *} p<0.001$ when compared with the only CFA-treated group.

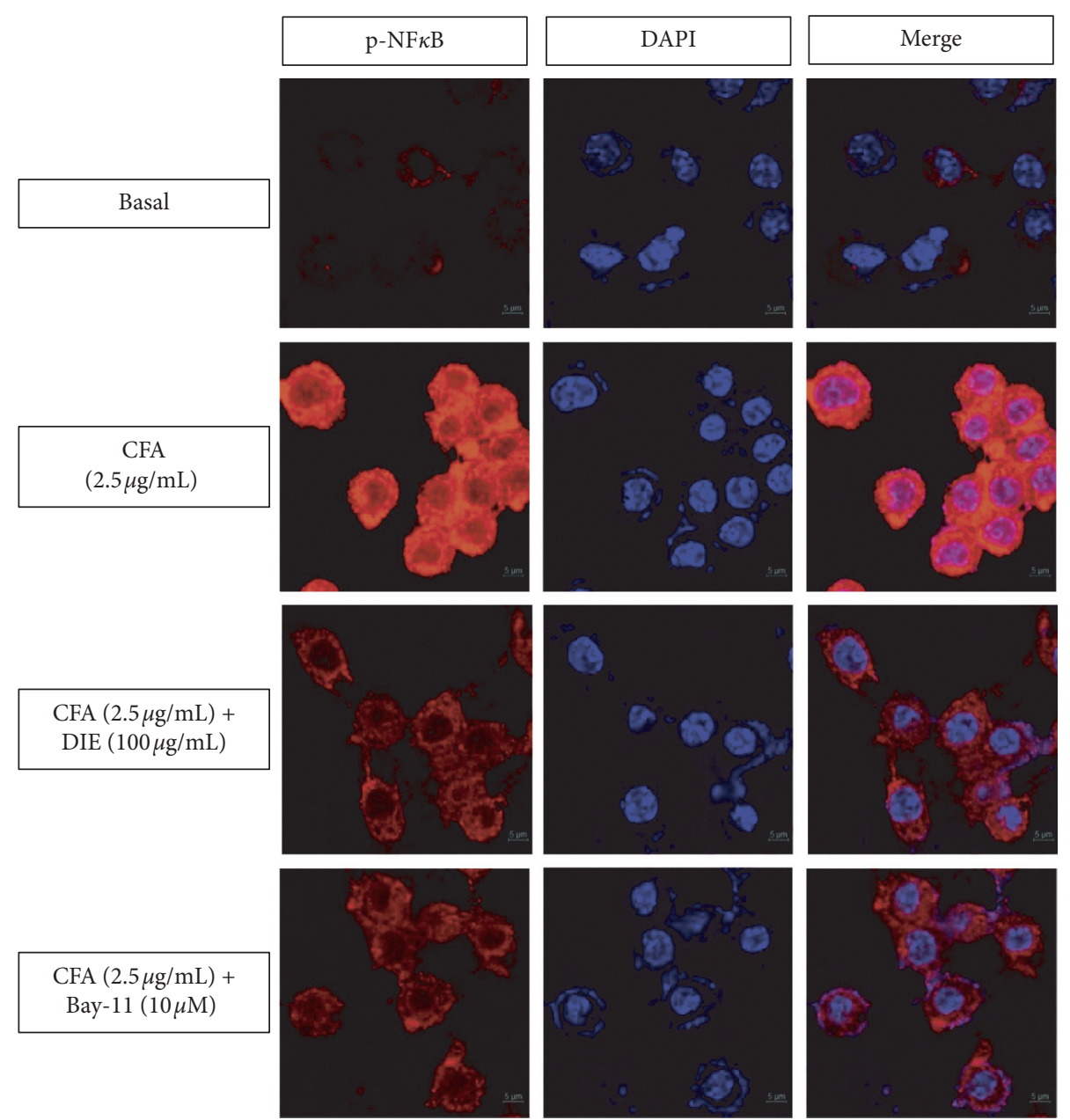

FIGURE 6: Effect of the DIE on CFA-induced NF- $\kappa$ B translocation in MH-S cells. The cells were seeded on coated cover slip in a six-well plate, and the groups were as follows: basal group, only CFA $(2.5 \mu \mathrm{g} / \mathrm{mL})$-induced group, CFA with the DIE (100 $\mu \mathrm{g} / \mathrm{ml})$ group, and CFA with Bay11 (inhibitor of p-NF- $\kappa \mathrm{B}$ ) group. The cells were treated with the DIE and Bay-11 (10 $\mu \mathrm{M})$ for 30 min prior to the CFA treatment $(2.5 \mu \mathrm{g} / \mathrm{mL})$ and were incubated for $18 \mathrm{~h}$. The nuclear translocation of $\mathrm{p}-\mathrm{NF}-\kappa \mathrm{B}$ was analyzed via immunofluorescence staining. The samples were mounted using ProLong ${ }^{\mathrm{TM}}$ Gold Antifade Reagent with DAPI to visualize the nuclei (blue). Stained cells were analyzed via confocal microscopy (ZEISS) at 1000x magnification. 


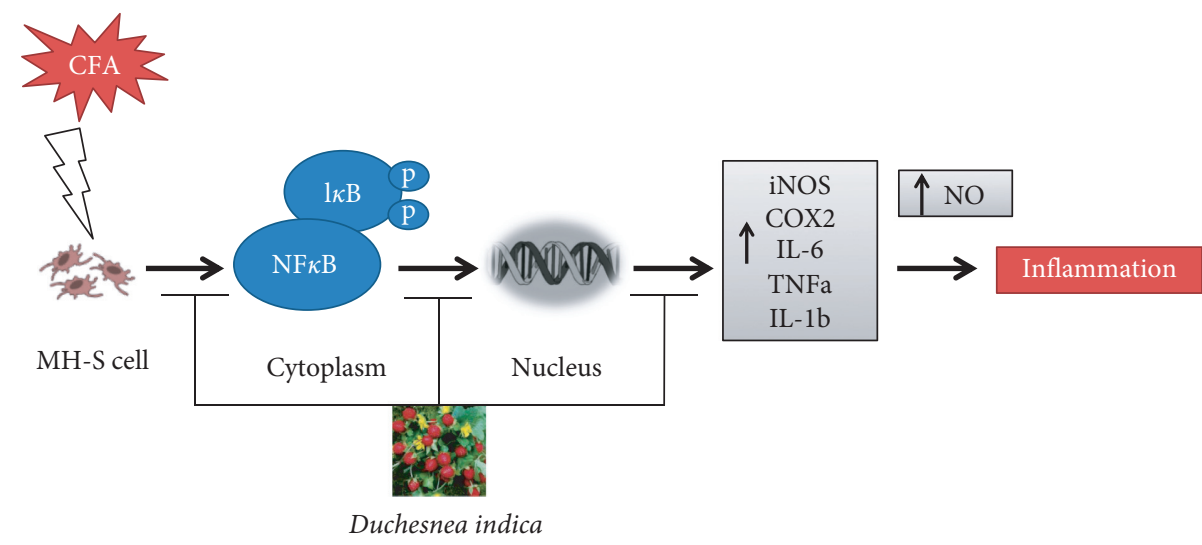

FIgURE 7: The mechanism of the DIE in CFA-induced inflammation in MH-S cells.

9,12,15-octadecatrienoic acid; gamma-sitosterol; octadecanoic acid; and linoelaidic acid. Although the DIE has antiinflammatory effects on CFA-induced inflammation in $\mathrm{MH}$ $S$ cells, further research is required to investigate the immune modulatory properties of the DIE in an animal model.

Particulate matter (PM) found in polluted air is becoming a major cause for health problems [28]. It has been reported that chronic exposure of PM is related to chronic inflammatory diseases especially severe lung diseases including chronic respiratory diseases, COPD, asthma, and mainly lung cancer $[1,29]$. Inflammatory disorders cause excessive production of proinflammatory mediators and cytokines, which are the critical factors of many pathological and clinical manifestations [30]. Macrophages are the immune cells found in the immune regulatory system and responsible for upregulating the generation of inflammatory mediators.

Nitric oxide (NO) is generated by the iNOS in activated macrophages. NO is a small signaling molecule with essential roles in numerous body functions, but unregulated NO production can cause pathophysiological activities in the airway system [31, 32]. Such disturbances can lead to airway narrowing and lung hypersensitivity. The results showed that the DIE reduced NO production in CFA-induced $\mathrm{MH}-\mathrm{S}$ cells, whereas NO production was markedly elevated in the only CFA-treated group. COX-2, which is another important proinflammatory mediator, plays a critical role in diverse inflammatory diseases [33]. In this study, it was found that the DIE suppressed the mRNA and protein expression levels of inflammatory mediators COX-2 and iNOS in CFA-activated MH-S cells.

Activated macrophages also generated other important proinflammatory cytokines, such as TNF- $\alpha$, IL-6, and IL- $1 \beta$, which are responsible for chronic inflammatory diseases and especially respiratory pathology [34]. IL-6 and TNF- $\alpha$ are the critical mediators of sepsis, and their uncontrolled regulation can cause cell death and DNA damage depending on the severity of cytokine production [9]. IL-1 $\beta$ increased the infiltration of inflammatory cells and mediated the activation of inflammatory cascade [35]. In the present study, the DIE inhibited the production of the IL- 6 , TNF- $\alpha$, and IL- $1 \beta$ mRNA expressions in CFA-activated MH-S cells. In this study, the DIE also suppressed the protein expression of iNOS and COX-2, suggesting that the DIE has anti-inflammatory properties.
It is well established that the transcription factor, NF$\kappa \mathrm{B}$, is a key regulator for inflammation in stimulated macrophages. In normal conditions, NF- $\kappa \mathrm{B}$ is stable in the cytoplasm; however, upon CFA stimulation, activated cells result in the phosphorylation of $\mathrm{I} \kappa \mathrm{B}$. Hence, the NF- $\kappa \mathrm{B}$ is disrupted to induce the phosphorylation, and activated NF- $\kappa \mathrm{B}$ translocates into the nucleus from the cytoplasm $[36,37]$. Thus, the $\mathrm{p}-\mathrm{NF}-\kappa \mathrm{B}$ then promotes the expression of proinflammatory mediators and cytokines. It has been previously shown that phosphorylated NF- $\kappa$ B increases the transcription of inflammatory genes [38]. The western blot results demonstrated that the DIE dose-dependently reduced the CFA-stimulated $\mathrm{I} \kappa \mathrm{B}$ and $\mathrm{NF}-\kappa \mathrm{B}$ phosphorylation in the cytoplasm. Moreover, the results of the immunofluorescence staining indicated that CFA increased the $\mathrm{p}-\mathrm{NF}-\kappa \mathrm{B}$ translocation in the nucleus, where the DIE $(100 \mu \mathrm{g} / \mathrm{mL})$ and Bay-11 $(10 \mu \mathrm{M})$ markedly inhibited the $\mathrm{p}-\mathrm{NF}-\kappa \mathrm{B}$ translocation from the cytoplasm to the nucleus. Based on our study, we speculated that the DIE might inhibit the phosphorylation of $\mathrm{I} \kappa \mathrm{B}$ and NF- $\kappa \mathrm{B}$ resulting in the suppressive activity of the proinflammatory cytokines. In our study, only in vitro experiment was carried out, but in vivo excrement should be done to determine the exact mechanism of action of DIE as an anti-inflammatory agent.

\section{Conclusion}

In summary, the current study demonstrated the anti-inflammatory properties of the DIE in the CFA-induced MH-S cell line. The obtained data provide important information about CFA-activated inflammatory responses and suggest that the DIE could inhibit the expression of proinflammatory mediators and cytokines in MH-S cells. These findings demonstrate that the DIE could be used as a promising bioactive functional food for immune modulation, especially in the treatment of lung inflammatory diseases.

\section{Data Availability}

All data generated during this study are included within this manuscript. 


\section{Conflicts of Interest}

The authors declare that there are no conflicts of interest regarding the publication of this article.

\section{Acknowledgments}

The authors thank Professor Man Hee Rhee, Ph.D., for his kind and cordial supervision, Yuan Yee Lee for the kind assistance, and Dong-Seon Kim for UPLC-QTOF-MS analysis of DIE. This study was funded and supported by the National Research Foundation (NRF) of Korea (2018R1D1A1A09083797).

\section{References}

[1] E. Saba, Y.-S. Lee, W.-K. Yang et al., "Effects of a herbal formulation, KGC3P, and its individual component, nepetin, on coal fly dust-induced airway inflammation," Scientific Reports, vol. 10, no. 1, pp. 1-13, 2020.

[2] K. K. A. Sanjeewa, T. U. Jayawardena, S.-Y. Kim et al., "Sargassum horneri (turner) inhibit urban particulate matterinduced inflammation in MH-S lung macrophages via blocking TLRs mediated NF- $\kappa \mathrm{B}$ and MAPK activation," Journal of Ethnopharmacology, vol. 249, Article ID 112363, 2020.

[3] J. Raudoniute, I. Stasiulaitiene, I. Kulvinskiene et al., "Proinflammatory effects of extracted urban fine particulate matter on human bronchial epithelial cells BEAS-2B," Environmental Science and Pollution Research, vol. 25, no. 32, pp. 3227732291, 2018.

[4] L. Hwang, I.-G. Ko, J.-J. Jin et al., "Attenuation effect of polydeoxyribonucleotide on inflammatory cytokines and apoptotic factors induced by particulate matter (PM10) damage in human bronchial cells," Journal of Biochemical and Molecular Toxicology, vol. 35, no. 2, Article ID e22635, 2021.

[5] R. D. Huff, C. Carlsten, and J. A. Hirota, "An update on immunologic mechanisms in the respiratory mucosa in response to air pollutants," Journal of Allergy and Clinical Immunology, vol. 143, no. 6, pp. 1989-2001, 2019.

[6] H. A. Ullah, S. Zaman, F. Juhara et al., "Evaluation of antinociceptive, in-vivo \& in-vitro anti-inflammatory activity of ethanolic extract of curcuma zedoaria rhizome," BMC Complementary Medicine and Therapies, vol. 14, no. 1, p. 346, 2014.

[7] Y. Han, X. Li, X. Zhang et al., "Isodeoxyelephantopin, a sesquiterpene lactone from elephantopus scaber linn., inhibits pro-inflammatory mediators' production through both NF$\kappa \mathrm{B}$ and AP-1 pathways in LPS-activated macrophages," International Immunopharmacology, vol. 84, Article ID 106528, 2020.

[8] J. Wu, Z. Yan, D. E. Schwartz, J. Yu, A. B. Malik, and G. Hu, "Activation of NLRP3 inflammasome in alveolar macrophages contributes to mechanical stretch-induced lung inflammation and injury," The Journal of Immunology, vol. 190, no. 7, pp. 3590-3599, 2013.

[9] T.-Y. Gil, B.-R. Jin, C.-H. Hong, J. H. Park, and H.-J. An, "Astilbe Chinensis ethanol extract suppresses inflammation in macrophages via NF- $\kappa \mathrm{B}$ pathway," BMC Complementary Medicine and Therapies, vol. 20, no. 1, pp. 1-11, 2020.

[10] Y. Y. Lee, W. K. Yang, J. E. Han et al., "Hypericum ascyron L. extract reduces particulate matter-induced airway inflammation in mice," Phytotherapy Research, vol. 35, no. 3, pp. 1621-1633, 2021.

[11] M. Zhu, X. Dong, and M. Guo, "Phenolic profiling of Duchesnea indica combining macroporous resin chromatography (MRC) with HPLC-ESI-MS/MS and ESI-IT-MS," Molecules, vol. 20, no. 12, pp. 22463-22475, 2015.

[12] W.-E. Yang, Y.-C. Ho, C.-M. Tang et al., "Duchesnea indica extract attenuates oral cancer cells metastatic potential through the inhibition of the matrix metalloproteinase-2 activity by down-regulating the MEK/ERK pathway," Phytomedicine, vol. 63, Article ID 152960, 2019.

[13] L. Zhao, S.-L. Zhang, J.-Y. Tao et al., "Anti-inflammatory mechanism of a folk herbal medicine, Duchesnea indica (andr) focke at RAW264.7 cell line," Immunological Investigations, vol. 37, no. 4, pp. 339-357, 2008.

[14] B. Peng, Q. Chang, L. Wang et al., "Suppression of human ovarian SKOV-3 cancer cell growth by duchesnea phenolic fraction is associated with cell cycle arrest and apoptosis," Gynecologic Oncology, vol. 108, no. 1, pp. 173-181, 2008.

[15] W. Hu, W. Han, C. Huang, and M.-H. Wang, "Protective effect of the methanolic extract from Duchesnea indica against oxidative stress in vitro and in vivo," Environmental Toxicology and Pharmacology, vol. 31, no. 1, pp. 42-50, 2011.

[16] H. Ullah, J. Kim, N. Rehman, H.-J. Kim, M.-J. Ahn, and H. Chung, "A simple and sensitive liquid chromatography with tandem mass spectrometric method for the simultaneous determination of anthraquinone glycosides and their aglycones in rat plasma: application to a pharmacokinetic study of rumex acetosa extract," Pharmaceutics, vol. 10, no. 3, p. 100, 2018.

[17] E. Saba, T. Shafeeq, M. Irfan et al., "Anti-inflammatory activity of crude venom isolated from parasitoid wasp, bracon hebetor say," Mediators of Inflammation, vol. 2017, Article ID 6978194, 11 pages, 2017.

[18] E. Saba, Y. Y. Lee, M. Kim et al., "A novel herbal formulation consisting of red ginseng extract and epimedium koreanum nakai-attenuated dextran sulfate sodium-induced colitis in mice," Journal of Ginseng Research, vol. 44, no. 6, pp. 833-842, 2020.

[19] H. M. A. Ullah, A. K. Elfadl, S. Park et al., "Nogo-A is critical for pro-inflammatory gene regulation in myocytes and macrophages," Cells, vol. 10, no. 2, p. 282, 2021.

[20] B. Peng, Q. Hu, X. Liu et al., "Duchesnea phenolic fraction inhibits in vitro and in vivo growth of cervical cancer through induction of apoptosis and cell cycle arrest," Experimental Biology and Medicine, vol. 234, no. 1, pp. 74-83, 2009.

[21] I. R. Lee and M. Y. Yang, "Phenolic compounds from duchesnea chrysantha and their cytotoxic activities in human cancer cell," Archives of Pharmacal Research, vol. 17, no. 6, pp. 476-479, 1994.

[22] J. M. Kim, D. S. Jang, Y. M. Lee et al., “Aldose-reductase- and protein-glycation-inhibitory principles from the whole plant of duchesnea chrysantha," Chemistry \& Biodiversity, vol. 5, no. 2, pp. 352-356, 2008.

[23] Y. Y. Lee, E. Saba, M. Irfan et al., "The anti-inflammatory and anti-nociceptive effects of Korean black ginseng," Phytomedicine, vol. 54, pp. 169-181, 2019.

[24] K. Muniandy, S. Gothai, K. M. Badran, S. Suresh Kumar, N. M. Esa, and P. Arulselvan, "Suppression of proinflammatory cytokines and mediators in LPS-induced RAW 264.7 macrophages by stem extract of via the inhibition of the NF-B pathway," Journal of Immunology Research, vol. 2018, Article ID 3430684, 12 pages, 2018. 
[25] F. Festa, T. Aglitti, G. Duranti, R. Ricordy, P. Perticone, and R. Cozzi, "Strong antioxidant activity of ellagic acid in mammalian cells in vitro revealed by the comet assay," $A n-$ ticancer Research, vol. 21, no. 6A, pp. 3903-3908, 2001.

[26] P.-C. Chao, C.-C. Hsu, and M.-C. Yin, "Anti-inflammatory and anti-coagulatory activities of caffeic acid and ellagic acid in cardiac tissue of diabetic mice," Nutrition \& Metabolism, vol. 6 , no. 1, p. 33, 2009.

[27] A. Aslan, O. Gok, O. Erman, and T. Kuloglu, "Ellagic acid impedes carbontetrachloride-induced liver damage in rats through suppression of NF- $\kappa \mathrm{B}, \mathrm{Bcl}-2$ and regulating Nrf-2 and caspase pathway," Biomedicine \& Pharmacotherapy, vol. 105, pp. 662-669, 2018.

[28] S.-B. Kim, Y.-S. Seo, H. S. Kim et al., "Anti-asthmatic effects of lepidii seu descurainiae semen plant species in ovalbumininduced asthmatic mice," Journal of Ethnopharmacology, vol. 244, Article ID 112083, 2019.

[29] R. W. Atkinson, S. Kang, H. R. Anderson, I. C. Mills, and H. A. Walton, "Epidemiological time series studies of PM2.5 and daily mortality and hospital admissions: a systematic review and meta-analysis," Thorax, vol. 69, no. 7, pp. 660-665, 2014.

[30] K. Van Reeth, "Cytokines in the pathogenesis of influenza," Veterinary Microbiology, vol. 74, no. 1-2, pp. 109-116, 2000.

[31] M. P. Murphy, "Nitric oxide and cell death," Biochimica et Biophysica Acta (BBA)-Bioenergetics, vol. 1411, no. 2-3, pp. 401-414, 1999.

[32] P. Dandona, A. Chaudhuri, and S. Dhindsa, "Proinflammatory and prothrombotic effects of hypoglycemia," American Diabetes Association, vol. 33, no. 7, pp. 1686-1687, 2010.

[33] E. Ricciotti and G. A. FitzGerald, "Prostaglandins and inflammation," Arteriosclerosis, Thrombosis, and Vascular Biology, vol. 31, no. 5, pp. 986-1000, 2011.

[34] F. M. Brennan and I. B. McInnes, "Evidence that cytokines play a role in rheumatoid arthritis," Journal of Clinical Investigation, vol. 118, no. 11, pp. 3537-3545, 2008.

[35] C. A. Dinarello, "Interleukin- $1 \beta$ and the autoinflammatory diseases," Massachusetts Medical Society, vol. 360, no. 23, pp. 2467-2470, 2009.

[36] W.-C. Huang and M.-C. Hung, "Beyond NF- $\kappa$ B activation: nuclear functions of I $\kappa$ B kinase $\alpha$," Journal of Biomedical Science, vol. 20, no. 1, pp. 1-13, 2013.

[37] S. Shoji, K. Hanada, M. Takahashi et al., "The NF- $\kappa$ B regulator $\mathrm{I} \kappa \mathrm{B} \beta$ exhibits different molecular interactivity and phosphorylation status from $\mathrm{I} \kappa \mathrm{B} \alpha$ in an IKK2-catalysed reaction," FEBS Letters, vol. 594, no. 10, pp. 1532-1549, 2020.

[38] P. J. Barnes and M. Karin, "Nuclear factor- $\kappa \mathrm{B}-\mathrm{a}$ pivotal transcription factor in chronic inflammatory diseases," New England Journal of Medicine, vol. 336, no. 15, pp. 1066-1071, 1997. 